\title{
EFFICACY EVALUATION OF THE ASSOCIATION OF SOME VEGETAL EXTRACTS IN PATIENTS SUFFERING FROM TRAUMATIC BRAIN INJURY. PILOT STUDY (II)
}

\author{
CONSTANTIN SORIN GODEANU ${ }^{1}$, DOINA MARIN ${ }^{1}$, LUMINIȚA STĂNCIULESCU ${ }^{1}$, \\ DANIELA GANE ${ }^{1}$, ANDREI VĂLEANU ${ }^{2 *}$, MANUELA GHICA ${ }^{2}$, DUMITRU LUPULIASA ${ }^{2}$, \\ CERASELA ELENA GÎRD ${ }^{2}$
}

'Department of Anaesthesia and Intensive Care Unit, "Floreasca" Emergency Clinical Hospital, 014461, Bucharest, Romania

2 "Carol Davila” University of Medicine and Pharmacy, Faculty of Pharmacy, 020956 Bucharest, Romania

*corresponding author: andrei.valeanu@umfcd.ro

\begin{abstract}
The aim of the current study was to evaluate the effects of health supplements as add-on treatment in patients suffering from cranio-cerebral trauma. During the entire monitoring period (21 days), several serum biomarkers were determined: sodium, potassium, haemoglobin, leukocytes, lymphocytes, urea, creatinine, C-reactive protein, as well as a continuous response variable: Glasgow Coma Scale. The clinical results indicated an improvement in terms of Glasgow Coma Scale compared to the control group.
\end{abstract}

\section{Rezumat}

Scopul studiului a fost de evalua efectele induse de asocierea în tratament la pacientii cu traumatism cranio-cerebral a unor suplimente alimentare. În toată perioada monitorizării (21 de zile) s-au evaluat parametrii sanguini: sodiu, potasiu, hemoglobina, leucocitele, limfocitele, ureea, creatinina, proteina C reactivă și s-a urmărit evoluția scorului Glasgow. Rezultatele clinice au arătat o îmbunătățire a stării de sănătate, comparativ cu lotul martor.

Keywords: traumatic brain injury, sea buckthorn juice

\section{Introduction}

Cranio-cerebral trauma is accompanied by high mortality $[3,14,21]$. Tissue damage is caused by primary physical injury, followed by secondary injury (several changes at a cellular and molecular level, such as cellular oedema and accumulation of immune and inflammatory mediators). Therapeutic interventions attenuate the secondary injury phase by diminishing the systemic inflammatory response syndrome $[6,11$, 22]. Mechanical ventilation, anaemic syndrome and seizure prevention, thromboprophylaxis and analgosedation are some of the most important therapeutic measures for polytraumatized patients [4]. Due to the amplitude and severity of cranio-cerebral trauma, as well as the prolonged hospitalization in the Neurosurgical Intensive Care Unit, the implementation of phytotherapeutic protocols (during hospitalization and after discharge) may be useful. Therefore, the aim of the present study was to assess the effect of a polyherbal dietary supplement (PDS) containing Urtica dioica, Taraxacum officinalis, Allium ursinum, Ranunculus ficaria and Rumex alpinus (Ursomax ${ }^{\circledR}$, Pontica Elidor, Romania) and sea buckthorn juice as add-on treatment on the health improvement of cranio-cerebral injury patients. The project issued from the idea of building a consistent and continuous relation between the patients' lifestyle before and after accident by the interlinked effort of a multidisciplinary team with long experience in traumatology.

\section{Materials and Methods}

Therapeutic protocol. The neurological resuscitation protocol, developed at the Clinical Emergency Hospital of Bucharest, Romania, was implemented for the administration of a polyherbal dietary supplement (PDS) containing Urtica dioica, Taraxacum officinalis, Allium ursinum, Ranunculus ficaria and Rumex alpinus (Ursomax ${ }^{\circledR}$, Pontica Elidor, Romania) to patients with neurotrauma from the Intensive Care Unit. The patients were divided into 2 groups: control group (5 patients with standard treatment) and treatment group (21 patients with PDS as an add-on treatment). In addition, because the partial results were not clinically significant, sea buckthorn juice were also added to the treatment group. The patients followed the treatment for 21 days. $15-20 \mathrm{~mL}$ of the suspension resulted from mixing the content of two tablets in distilled water and sea buckthorn juice $(10 \mathrm{~mL} / \mathrm{kg} / \mathrm{day})$ were administered through a nasogastric tube [3]. The combination was administered three times per day and the patients, at 
least two hours before and after meals. During monitoring, the following blood serum parameters were determined: Sodium (Na), Potassium (K), haemoglobin, leukocytes, lymphocytes, urea, creatinine, C-reactive protein (CRP). In addition, the Glasgow Coma Scale (GCS) was determined. All the blood serum determinations were undertaken in the hospital's clinical laboratory. The Therapeutic Protocol was approved by the hospital's Local Ethics Committee and an informed consent was signed by the patients' family members. Preliminary statistical analysis. In order to offer a general description of the obtained dataset, a preliminary statistical analysis was carried out. The mean and standard deviation were computed for each of the 9 parameters. In addition, the Pearson correlation coefficient, along with the $\mathrm{p}$-value for statistical significance, was determined between each pair of parameters [13]. The statistical indicators (mean, standard deviation, Pearson correlation coefficient) were computed for each group of patients (treatment and control) and for each time interval $(1,4,7,10,13,16,19$ day(s)). Python Programming Language version 3.9.2 was used for performing the preliminary statistical analysis [13]. Data analysis. The proper data analysis was performed using open-source software R. The dataset is longitudinal, characterized by repeated measurements every 3 days, performed on the same individual over 19 days. The individuals were divided into two groups. The first group, consisting of 5 individuals, received only the medication related to the disease in research and it is considered a control group. The second group, consisting of 21 individuals, received medication for the disease and dietary supplements and it is considered a treatment group. The main purpose of this longitudinal study is to characterize the changes observed over time (19 days) in 8 continuous explanatory variables: Sodium (Na), Potassium (K), haemoglobin, leukocytes, urea, lymphocytes, creatinine, C-reactive protein (CRP) and a continuous response variable: Glasgow Coma Scale (GCS). It is also important to highlight the differences between the two groups: control and treatment. Because the conditions of normality and homoscedasticity are partially met, we used a robust method for ANOVA with 2 factors with repeated measures [10]. We also applied post hoc comparisons relative to a single effect based on the bootstrap approach [1, 2].

To evaluate the differences between the studied groups, several statistical evaluation methods were used [1, $2,10]$. This way we can establish if the differences between the two study groups are significant using the $5 \%$ standard level of significance $(\mathrm{p}<0.05)$.

\section{Results and Discussion}

The clinical results obtained on the patients which followed the treatment were satisfactory, even when considering the patients with a GCS of 3 (multiple organ dysfunctions) when admitted to the ICU.

The incidence of sodium imbalances is quite high $(45 \%)$ in patients with subdural hematoma. As an example, intravenous administration of mannitol can cause high serum sodium levels. Hyponatraemia can be followed by hypokalaemia in certain patients and it should be noted that a serum potassium level of less than $2.5 \mathrm{mmol} / \mathrm{L}$ significantly raises the risk for life threatening arrhythmias $[8,18]$. Therefore, it is very important to maintain a physiological sodium/ potassium balance in order to prevent complications. From a therapeutic point of view, an improvement in sodium levels was observed since day 4 of treatment. Anaemia is a frequent consequence of traumatic brain injury and is associated with negative outcomes. However, anaemia-induced cerebral hypoxia causes the production of hypoxia inducible factors (HIF) which enhance erythropoietin secretion. This adaptive mechanism prevents neuronal apoptosis, has neuroprotective effects, stimulates angiogenesis and maintains a minimum level of tissue oxygenation $[12,17]$. The contribution of leukocytes in the development of cerebral ischemia is explained by the acute inflammatory response from the secondary injury. The acute inflammation phase causes enhanced microvascular permeability, vasodilation and blood flow alterations $[15,26]$. In addition, the ratio between neutrophils and lymphocytes (NLR) is an important inflammation marker [7, 24]. Several studies showed that a high NLR is correlated with a low GCS. For example, the patients suffering from severe traumatic brain injury usually experience alterations in cellular immune function in the first 7 days, with nearly $75 \%$ of them developing pulmonary infections $[5,20]$. Serum urea and creatinine, other two important biomarkers quantified in the current study are important parameters for patients' evolution. It should be noted that their values usually normalize as long as the complications (inflammatory syndrome, septic shock, pulmonary embolism) are avoided [5, 20]. In addition, C-reactive protein (CRP) was another serum parameters which was quantified in the present work. CRP is an essential systemic inflammation biomarker and high values are correlated with negative outcomes. Traumatic brain injury induces cerebral inflammation; CRP is produced by the liver, as a part of the acute systemic inflammatory response [19]. In the present study, CRP reached its peak values within the first 3 days. Last but not least, GCS, an important parameter which was determined in the current study, is a widely used clinical instrument which evaluates the coma level through a score which is obtained as a sum of responses which are quantified by the following criteria: verbal, ocular, motor [16]. The patients enrolled in the study were included the GCS 3 - 8 category (severe cerebral trauma). The GCS evaluation had the advantage of allowing a personalized therapeutic approach. 
Mean ( \pm standard deviation) of the biochemical parameters within the treatment group (21 patients)

\begin{tabular}{|c|c|c|c|c|c|c|c|c|c|}
\hline Day & $\mathrm{Na}$ & $\mathrm{K}$ & $\mathrm{Hb}$ & $\mathrm{Leu}$ & $\mathrm{Lim}$ & $\mathrm{Ur}$ & $\mathrm{Cr}$ & $\mathrm{CRP}$ & GCS \\
\hline 1 & 149.74 & 4.56 & 8.65 & 12710.9 & 1436.62 & 128.54 & 1.43 & 45.48 & 3.9 \\
& $( \pm 10.51)$ & $( \pm 1.05)$ & $( \pm 1.67)$ & $( \pm 5134.51)$ & $( \pm 1808.04)$ & $( \pm 32.41)$ & $( \pm 0.33)$ & $( \pm 18.92)$ & $( \pm 1.02)$ \\
\hline 4 & 146.56 & 4.5 & 9.64 & 12543.71 & 1474.19 & 113.56 & 1.29 & 105.14 & 5.43 \\
& $( \pm 8.41)$ & $( \pm 0.91)$ & $( \pm 1.2)$ & $( \pm 3910.87)$ & $( \pm 2156.1)$ & $( \pm 24.0)$ & $( \pm 0.25)$ & $( \pm 21.34)$ & $( \pm 1.0)$ \\
\hline 7 & 143.42 & 4.45 & 10.71 & 12177.48 & 1678.81 & 103.03 & 1.12 & 80.33 & 7.67 \\
& $( \pm 3.71)$ & $( \pm 0.87)$ & $( \pm 1.35)$ & $( \pm 3225.72)$ & $( \pm 1783.06)$ & $( \pm 19.29)$ & $( \pm 0.24)$ & $( \pm 9.37)$ & $( \pm 1.32)$ \\
\hline 10 & 142.17 & 4.02 & 11.13 & 12044.67 & 1694.86 & 85.95 & 0.94 & 52.52 & 14.9 \\
& $( \pm 4.08)$ & $( \pm 0.79)$ & $( \pm 1.22)$ & $( \pm 1890.1)$ & $( \pm 845.38)$ & $( \pm 14.32)$ & $( \pm 0.19)$ & $( \pm 13.11)$ & $( \pm 25.54)$ \\
\hline 13 & 142.07 & 4.05 & 12.09 & 11370.76 & 2586.86 & 71.46 & 1.1 & 30.48 & 11.48 \\
& $( \pm 3.42)$ & $( \pm 0.85)$ & $( \pm 1.41)$ & $( \pm 1803.99)$ & $( \pm 3436.43)$ & $( \pm 11.52)$ & $( \pm 1.23)$ & $( \pm 13.69)$ & $( \pm 1.53)$ \\
\hline 16 & 141.19 & 4.06 & 13.29 & 10766.19 & 2491.33 & 65.67 & 0.7 & 13.38 & 13.57 \\
& $( \pm 2.86)$ & $( \pm 0.83)$ & $( \pm 2.36)$ & $( \pm 1733.32)$ & $( \pm 2149.59)$ & $( \pm 9.59)$ & $( \pm 0.13)$ & $( \pm 3.81)$ & $( \pm 0.85)$ \\
\hline 19 & 142.53 & 4.11 & 13.04 & 10665.67 & 2650.33 & 58.17 & 0.63 & 5.33 & 14.95 \\
& $( \pm 2.34)$ & $( \pm 0.85)$ & $( \pm 1.14)$ & $( \pm 1664.05)$ & $( \pm 2333.12)$ & $( \pm 7.85)$ & $( \pm 0.11)$ & $( \pm 1.83)$ & $( \pm 0.21)$ \\
\hline
\end{tabular}

*Legend: $\mathrm{Na}=$ natremia, $\mathrm{K}=$ kalemia, $\mathrm{Hb}=$ serum haemoglobin, Leu = leukocyte count, Lim = lymphocyte count, Ur = blood urea nitrogen, $\mathrm{Cr}=$ serum creatinine, $\mathrm{CRP}=\mathrm{C}$-reactive protein, $\mathrm{GCS}=$ Glasgow Scale Score

Table II

Mean ( \pm standard deviation) of the biochemical parameters within the control group (5 patients)

\begin{tabular}{|c|c|c|c|c|c|c|c|c|c|}
\hline Day & $\mathrm{Na}$ & $\mathrm{K}$ & $\mathrm{Hb}$ & $\mathrm{Leu}$ & $\mathrm{Lim}$ & $\mathrm{Ur}$ & $\mathrm{Cr}$ & $\mathrm{CRP}$ & GCS \\
\hline 1 & 150.0 & 4.33 & 7.85 & 14597.0 & 1231.4 & 125.2 & 1.62 & 73.2 & 3.4 \\
& $( \pm 6.63)$ & $( \pm 0.79)$ & $( \pm 1.52)$ & $( \pm 3471.36)$ & $( \pm 732.03)$ & $( \pm 19.1)$ & $( \pm 0.07)$ & $( \pm 16.7)$ & $( \pm 0.49)$ \\
\hline 4 & 145.6 & 4.5 & 9.16 & 15273.6 & 1208.0 & 112.0 & 1.45 & 153.2 & 3.6 \\
& $( \pm 4.13)$ & $( \pm 0.72)$ & $( \pm 1.18)$ & $( \pm 2019.8)$ & $( \pm 426.65)$ & $( \pm 14.01)$ & $( \pm 0.11)$ & $( \pm 25.02)$ & $( \pm 0.49)$ \\
\hline 7 & 144.4 & 4.46 & 9.95 & 16547.8 & 1566.4 & 97.4 & 1.41 & 107.8 & 4.8 \\
& $( \pm 4.08)$ & $( \pm 0.44)$ & $( \pm 1.04)$ & $( \pm 1462.76)$ & $( \pm 585.23)$ & $( \pm 6.59)$ & $( \pm 0.19)$ & $( \pm 14.47)$ & $( \pm 0.75)$ \\
\hline 10 & 144.6 & 4.54 & 11.62 & 15707.4 & 1505.2 & 83.4 & 1.22 & 69.4 & $\begin{array}{c}5.8 \\
( \pm 0.75)\end{array}$ \\
& $( \pm 4.32)$ & $( \pm 0.26)$ & $( \pm 1.5)$ & $( \pm 2502.29)$ & $( \pm 610.27)$ & $( \pm 5.89)$ & $( \pm 0.23)$ & $( \pm 9.31)$ & $( \pm 2.49 .4$ \\
13 & 144.6 & 4.37 & 12.37 & 13953.2 & 1352.0 & 77.0 & 0.98 & 48.2 & 6.4 \\
& $( \pm 2.42)$ & $( \pm 0.31)$ & $( \pm 1.52)$ & $( \pm 1926.09)$ & $( \pm 409.95)$ & $( \pm 6.57)$ & $( \pm 0.15)$ & $( \pm 13.66)$ & $( \pm 0.49)$ \\
\hline 16 & 142.2 & 4.19 & 12.86 & 12203.6 & 1416.8 & 71.4 & 0.8 & 22.2 & 7.0 \\
& $( \pm 3.25)$ & $( \pm 0.37)$ & $( \pm 1.24)$ & $( \pm 1646.16)$ & $( \pm 244.4)$ & $( \pm 3.83)$ & $( \pm 0.19)$ & $( \pm 6.79)$ & $( \pm 0.63)$ \\
\hline 19 & 142.0 & 4.28 & 13.7 & 11603.2 & 1867.2 & 57.6 & 0.74 & 13.0 & 7.6 \\
& $( \pm 3.1)$ & $( \pm 0.26)$ & $( \pm 0.64)$ & $( \pm 743.81)$ & $( \pm 638.08)$ & $( \pm 6.97)$ & $( \pm 0.27)$ & $( \pm 4.52)$ & $( \pm 0.49)$ \\
\hline
\end{tabular}

*Legend: $\mathrm{Na}=$ natremia, $\mathrm{K}=$ kalemia, $\mathrm{Hb}=$ serum haemoglobin, Leu = leukocyte count, Lim = lymphocyte count, Ur = blood urea nitrogen, $\mathrm{Cr}=$ serum creatinine, $\mathrm{CRP}=\mathrm{C}$-reactive protein, $\mathrm{GCS}=$ Glasgow Scale Score

\section{Preliminary statistical analysis}

Tables I and II present the results obtained in terms of mean and standard deviation for the treatment and control groups.

Figures 1, 2 and 3 present the most clinically relevant results obtained in terms of correlation analysis. It should be noted that no results were included for the control group, due to the low number of patients (5), which yielded unreliable results.

According to the obtained results in terms of correlation analysis (Figures 1,2 and 3), it should be noted that several statistically significant results were obtained. First of all, for day 1 since treatment started (Figure 1), negative correlations were obtained between serum sodium and C-reactive protein (correlation coefficient = -0.46 , p-value for statistical significance of 0.0382), as well as between serum potassium and serum creatinine (correlation coefficient $=-0.62, \mathrm{p}$-value $=0.0026$ ) By contrast, the analysis yielded significant positive correlations between serum potassium and C-reactive protein $($ correlation coefficient $=0.48, \mathrm{p}$-value $=0.0264$ ) and between blood urea and serum creatinine (correlation coefficient $=0.55, \mathrm{p}$-value $=0.0098$ ).

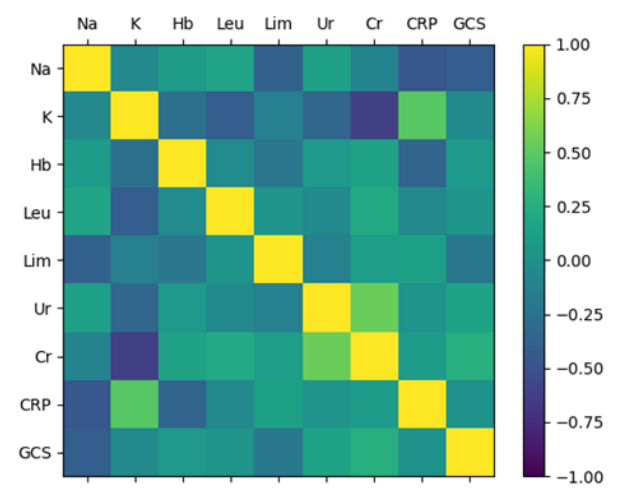

Figure 1.

Correlation analysis results for treatment group, day 1 $\mathrm{Na}=$ natremia, $\mathrm{K}=$ kalemia, $\mathrm{Hb}=$ serum haemoglobin, Leu = leukocyte count, Lim = lymphocyte count, $\mathrm{Ur}=$ blood urea nitrogen, $\mathrm{Cr}=$ serum creatinine, $\mathrm{CRP}=\mathrm{C}$-reactive protein, GCS = Glasgow Scale Score; -1.00 to 1.00 range $=$ Pearson correlation coefficient 


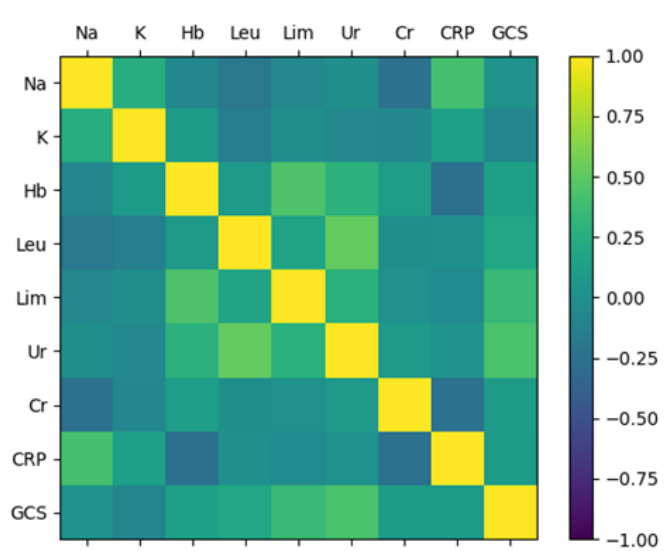

Figure 2.

Correlation analysis results for treatment group, day 13 $\mathrm{Na}=$ natremia, $\mathrm{K}=$ kalemia, $\mathrm{Hb}=$ serum haemoglobin, Leu = leukocyte count, $\mathrm{Lim}=$ lymphocyte count, $\mathrm{Ur}=$ blood urea nitrogen, $\mathrm{Cr}=$ serum creatinine, $\mathrm{CRP}=\mathrm{C}$-reactive protein, $\mathrm{GCS}=$ Glasgow Scale Score; -1.00 to 1.00 range $=$ Pearson correlation coefficient

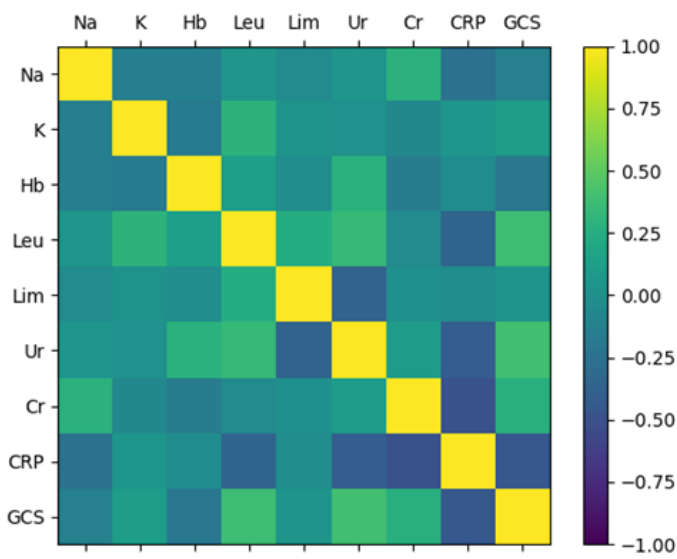

Figure 3.

Correlation analysis results for treatment group, day 19 $\mathrm{Na}=$ natremia, $\mathrm{K}=$ kalemia, $\mathrm{Hb}=$ serum haemoglobin, Leu = leukocyte count, Lim = lymphocyte count, $\mathrm{Ur}=$ blood urea nitrogen, $\mathrm{Cr}=$ serum creatinine, $\mathrm{CRP}=\mathrm{C}$-reactive protein, $\mathrm{GCS}=$ Glasgow Scale Score; -1.00 to 1.00 range $=$ Pearson correlation coefficient

Indeed, it should be noted that the relationships between the serum values of sodium/potassium and the Creactive protein have been emphasized by Yilmaz et $a l$., whose findings showed a positive relationship between high salt intake and an inflammatory status, as quantified through CRP. It should therefore be noted that the negative correlation between serum sodium and CRP (and positive correlation between serum potassium and CRP) obtained in the current study could be due to the compensatory mechanism of enhanced urinary sodium excretion in patients with high salt intake [25].
In addition, the positive relationship between serum potassium and CRP could be due to altered renal function in certain patients, since higher serum potassium levels have found to be the effect of chronic kidney disease, which also involves altered CRP levels [23]. However, the majority of the patients enrolled in the current study had normal kalemia, so it is difficult to judge this clinical aspect solely based on this. Secondly, in day 13 of treatment (Figure 2), a significant positive relationship was identified between blood urea levels and the Glasgow Scale Score (GCS) (correlation coefficient $=0.43$, p-value $=0.0527$ ). In addition, in day 19 of treatment (Figure 3), significant negative correlations were found between serum creatinine and CRP (correlation coefficient $=-0.50, \mathrm{p}$-value $=0.0223$ ), as well as between CRP and GCS (correlation coefficient $=-0.45, \mathrm{p}$-value $=0.0399$ ). Indeed, the significantly lower levels of inflammation in day 19 (Table I - average CRP levels in treatment group: day 1 - 45.48, day 13 - 30.48, day 19 - 5.33) were inversely related to the higher values of GCS (Table I - average GCS levels in treatment group: day 1 - 3.9, day 13 11.48 , day 19 - 14.95). The patients in the treatment group had at day 19 lower levels of inflammation and an improved GCS, which has been found to lead to better outcomes. Leitgeb et al. showed that a GCS less than 10 at discharge puts the patients at risk of a less favourable outcome [9].

\section{Data analysis}

To statistically determine how explanatory parameters influence the Glasgow score, we analysed several regression models, both simple and multiple. To decide the best regression model as well as the number of explanatory parameters we used Akaike's Information Criterion (AIC). Thus, the Glasgow score is optimally predicted (AIC $=826.2$ ) by in a multiple linear regression model in relation to $\mathrm{C}$-reactive protein, Creatinine and belonging to a certain group $(\mathrm{p}<0.001$, adjusted $\mathrm{R}$-squared $=0.662$ ). There was a significant relationship between Glasgow score and C-reactive protein $(\mathrm{p}<0.001)$, Glasgow score and Creatinine $(p<0.001)$ and belonging to the treatment group and Glasgow score $(\mathrm{p}<0.001)$. For C-reactive protein, there was 0.03 points increase in Glasgow score for each less 1 U.M. of C-reactive protein and with 5.58 points increases in Glasgow score for each less 1 U.M. of Creatinine. It is important to note that individuals from treatment group have the Glasgow score with 2.25 higher than individuals from control group. The adjusted R-squared value was 0.662 so $66.2 \%$ of the variation of Glasgow score can be explained by the model containing C-reactive protein, creatinine and whether the individual is treated or not with dietary supplements. The data met all assumptions for multiple linear regression (Figures 4, 5 and 6). 

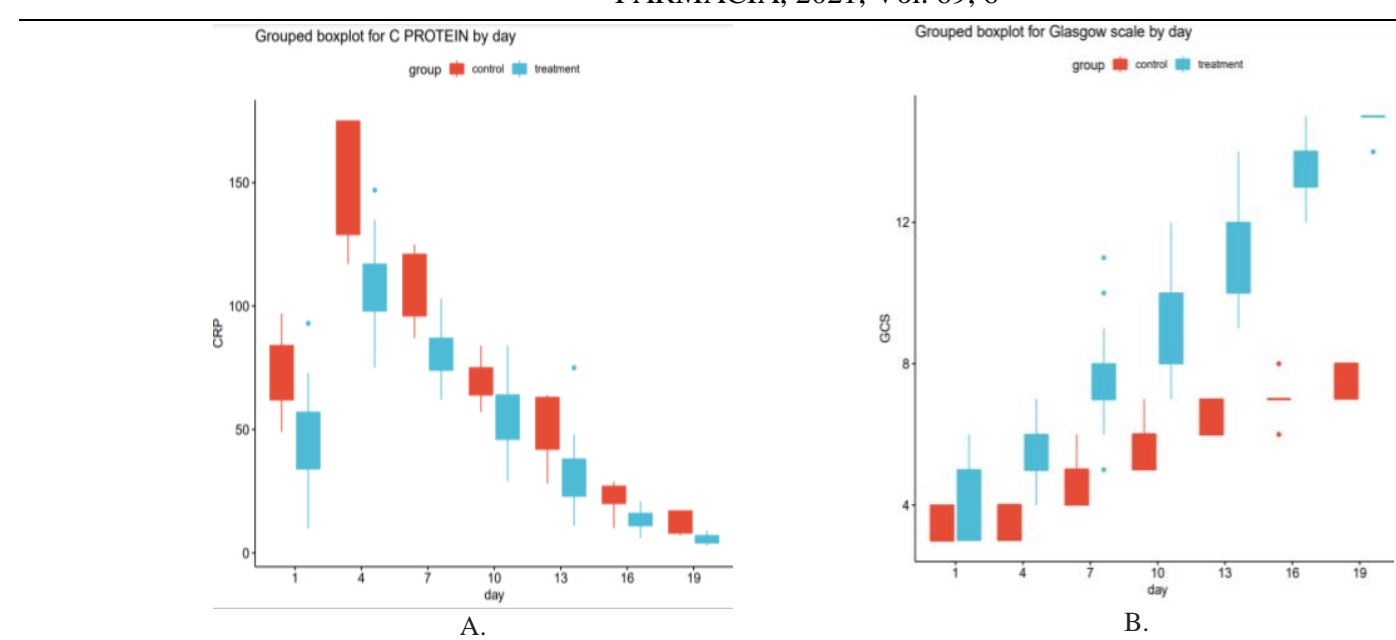

Figure 4.

Daily evolution of several parameters

A. CRP - C-reactive protein; B. GCS - Glasgow Coma Scale
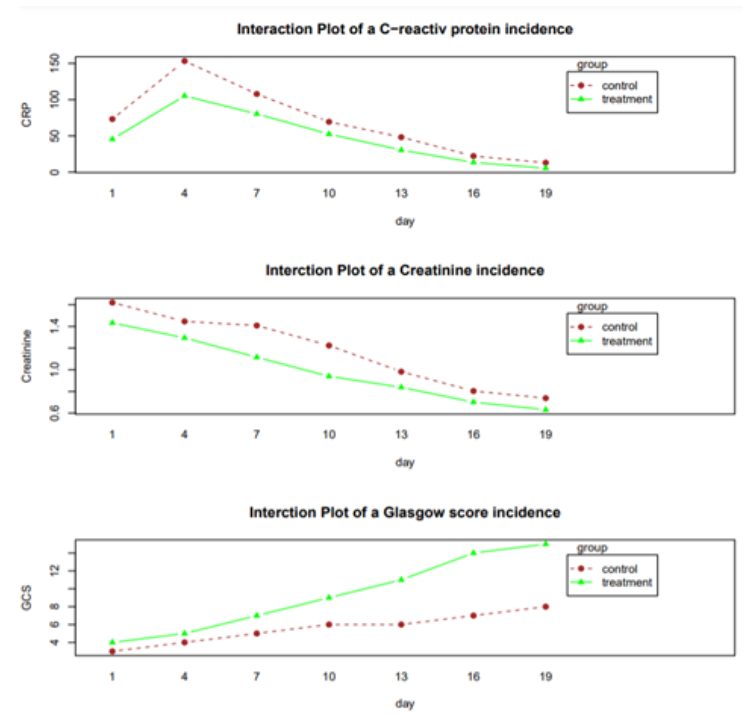

Figure 5.

Interactions of several variables

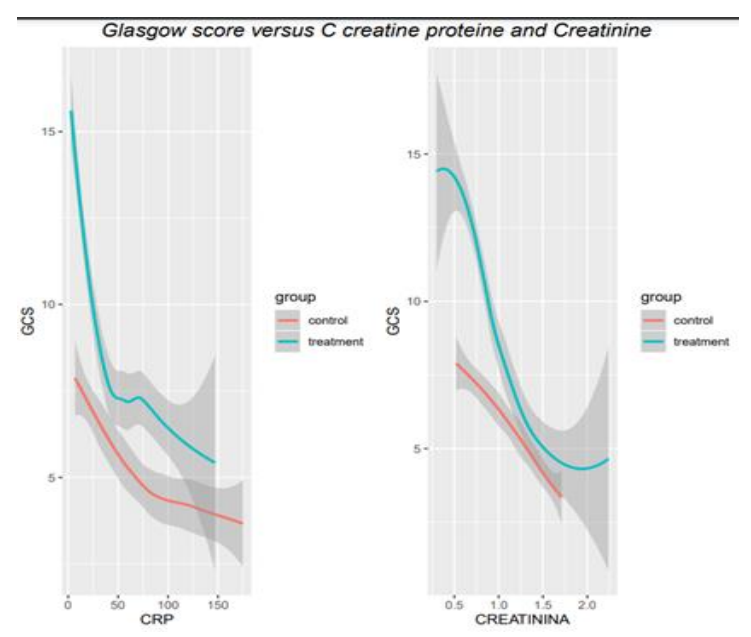

Figure 6.

Variation of Glasgow score versus C-reactive protein and Creatinine

\section{Conclusions}

An observational pilot study for evaluating the effect of the combination between the studied polyherbal dietary supplement and sea buckthorn juice as add-on treatment in patients suffering from traumatic brain injury was designed and undertaken. The analysis yielded improved health outcomes in terms of Glasgow Coma Scale for the patients in the treatment group. Future studies must focus in developing randomized controlled trials in order to clinically validate the obtained results.

\section{Conflict of interest}

The authors declare no conflict of interest.

\section{References}

1. Albeanu G, Ghica M, Popentiu-Vladicescu F, On using bootstrap scenario-generation for multi-period stochastic programming applications. Int J Computers, Communications \& Control, 2008; 3, 156-161.

2. Ghica M, Bancescu I, Udeanu DI, How we Deal with Small Data?, Proceedings Of The Romanian National Congress Of Pharmacy, $17^{\text {th }}$ Edition: $21^{\text {st }}$ Century Pharmacy - Between Intelligent Specialization And Social Responsibility, 2018; 84-87.

3. Godeanu CS, Costea T, Chica M, Lupuliasa D, Gîrd $\mathrm{CE}$, Evidence-based use of sea buckthorn fresh juice for patients with traumatic brain injury. A pilot study. Farmacia, 2020; 68(3): 541-546.

4. Grande PO, The lund concept for the treatment of patients with severe traumatic brain injury. J Neurosurg Anesthesiol., 2011; 23: 358-362.

5. Gul FH, Dolanbay T, Simsek AT, Aras M, Evaluation of blood urea, creatinine and glucose levels as biochemical indicators of the type and severity of traumatic brain injury. Turk Neurosurg., 2021; 31(3): 333-338.

6. Ichai C, Ciais JF, Grimaud D, The internal environment and intracranial hypertension. Anesth Reanim., 1997; 16: 435-444. 
7. Jigang C, Xiaolin Q, Zhenxing L, Danfeng Z, Lijun H, Peak Neutrophil-to-Lymphocyte ratio correlates with clinical outcomes in patients with severe traumatic brain injury. Neurocrit Care, 2019; 30: 334-339.

8. Kruse JA, Carlson RW, Rapid Correction of Hypokalemia Using Concentrated Intravenous Potassium Chloride Infusions. Arch Intern Med., 1990; 150(3): 613-617.

9. Leitgeb J, Mauritz W, Brazinova A, Majdan M, Janciak I, Wilbacher I, Rusnak M, Glasgow Coma Scale score at intensive care unit discharge predicts the 1-year outcome of patients with severe traumatic brain injury. Eur J Trauma Emerg Surg., 2013; 39(3): 285-292.

10. Mair P, Wilcox R, Robust statistical methods in R using the WRS2 package. Behav Res Methods, 2020; 52(2): 464-488.

11. Narotam PK, Morrison JF, Nathoo N, Brain tissue monitoring in traumatic brain injury and major trauma: outcome analysis of a brain tissue oxygen - directed therapy. J Neurosurg., 2009; 111: 672-82.

12. Păunescu C, Pițigoi G, Cosma G, Pițuru SM, Grigore V, Petrescu S, Mircică ML, Rădulescu M, Cosma A, Rezaee R, Petrescu OC, Increasing endurance in physical effort by administration of inosine. Farmacia, 2021; 69(1): 148-154.

13. Python Software Foundation, Python Language Reference, version 3.9.2, 2021; www.python.org/ downloads/release/python-392/.

14. Qiang Yuan, Xing Wu, Yirui Sun, Jian Yu, Zhigi Li, Zhuoying Du, Ying Mao, Liangfu Zhou, Jin Hu, Impact of intracranial pressure monitoring on maortality in patiens with traumatic brain injury: A systematic reviw and meta-analysis. J. Neurosurg., 2015; 122: 574-587.

15. Sabri M, Lass E, Loch Macdonald R, Early brain injury: a common mechanism in subarachnoid hemorrhage and global cerebral ischemia. Stroke Res Treat., 2013; 2013: 394036: 1-9.

16. Saika A, Bansal S, Philip M, Indira Devi B, Shukla DP, Prognostic value of FOUR and GCS scores in determining mortality in patients with traumatic brain injury. Acta Neurochirurgica, 2015; 157: 1323-1328.
17. Salim A, DuBose J, Brown C, Inaba K, Chan L, Margulies DR, Role of anemia in traumatic brain injury. J Am Coll Surg., 2008; 207(3): 398-406.

18. Schaefer M, Link J, Hannemann L, Rudolph KH, Excessive hypokalemia and hyperkalemia following head injury. Intensive Care Med, 1995; 21:235-237.

19. Shetty T, Cogsil T, Dalal A, Kim E, Halvorsen K, Cummings K, Nguyen JT, High-Sensitivity C-Reactive Protein: Retrospective Study of Potential Blood Biomarker of Inflammation in Acute Mild Traumatic Brain Injury. J Head Trauma Rehabil., 2019; 34(3): E28-E36.

20. Udy A, Boots R, Senthuran S, Stuart J, Deans R, Lassing-Smith M, Lipman J, Augmented creatinine clearance in traumatic brain injury. Anesth Analg., 2010; 111(6): 1505-1510

21. Vaaroma K, Puliula J, Tetri S,Juvela S, Hillbom M, Increases the risk of future traumatic death: a control prospective 15-year follow-up study. J Neurotrauma, 2015; 32(20): 1-7.

22. Van den Brink WA, Van Santbrink H, Steyerberg EW, Aveezat CJ, Suazo JA, Hogeesteger C, Jansen WJ, Kloos LM, Vermeulen J, Maas Al, Brain oxygen tension in severe head injury. Neurosurgery, 2000; 46: 868-76.

23. Watanabe R, Hyperkalemia in chronic kidney disease. Rev Assoc Med Bras (1992), 2020; 66(Suppl 1): s31-s36.

24. Weigiang C, Jinhua Y, Guovi P, Tianfei L, Lianiie L, Shousn W, Neurophil to lymphocyte ratio as a novel predictor of outcome in patients with severe traumatic brain injury. J Head Trauma Rehabil., 2018; 33(1): E53-E59.

25. Yilmaz R, Akoglu H, Altun B, Yildirim T, Arici M, Erdem Y, Dietary salt intake is related to inflammation and albuminuria in primary hypertensive patients. Eur J Clin Nutr., 2012; 66: 1214-1218.

26. Ziebell JM, Morganti-Kossmann MC, Involvement of pro- and anti-inflammatory cytokines and chemokines in the pathophysiology of traumatic brain injury. Neurotherapeutics, 2010; 7: 22-30. 